\title{
Designing Simulations for Athletic Training Students Through Interprofessional Teaching Collaboration
}

\author{
Kristin Tivener \\ Missouri State Univeristy \\ Donna Gloe \\ Missouri State Univeristy
}

Follow this and additional works at: https://bearworks.missouristate.edu/articles-chhs

\section{Recommended Citation}

Tivener, Kristin Ann, and Donna Sue Gloe. "Designing Simulations for Athletic Training Students Through Interprofessional Teaching Collaboration." Athletic Training Education Journal 10, no. 3 (2015): 249-255.

This article or document was made available through BearWorks, the institutional repository of Missouri State University. The work contained in it may be protected by copyright and require permission of the copyright holder for reuse or redistribution.

For more information, please contact BearWorks@library.missouristate.edu. 


\title{
Designing Simulations for Athletic Training Students Through Interprofessional Teaching Collaboration
}

\author{
Kristin Ann Tivener, MET, ATC*; Donna Sue Gloe, EdD, RN-BC† \\ *Department of Sports Medicine and Athletic Training, Missouri State University, Springfield; \\ $\dagger$ Department of Nursing, Missouri State University, Springfield
}

Context: While multidisciplinary team approaches to education and practice have been promoted for decades, literature on collaborative efforts in athletic training and nursing remains sparse.

Objective: The goal of this article is to provide an example of an interprofessional teaching collaboration in which a simulation scenario was developed between athletic training and nursing education faculty members and to outline the observed benefits and barriers arising from this approach.

Background: Interprofessional education and interdepartmental faculty collaboration are increasingly becoming more established and practiced elements of health professionals' education. Bringing together professionals from diverse but interrelated disciplines in a collaborative teaching activity can enhance students' understanding of the health care system and the technical expertise each professional provides in emergent situations.

Description: In many health care education programs simulation has been increasingly used as a teaching tool to provide students with opportunities to practice and learn in an environment that mirrors reality as closely as possible. An example of a simulation scenario developed through an interprofessional teaching collaborative is provided as a foundational design for reproduction.

Clinical Advantage(s): Interprofessional teaching collaboration of athletic training and nursing faculty can greatly enhance the content and realism of cardiopulmonary simulation for athletic training students when it involves the combined knowledge and experience of these 2 disciplines.

Conclusion(s): Interprofessional teaching collaboration in simulation scenarios can greatly enhance learning insights and clinical relevance for athletic training students.

Key Words: Education, nursing, faculty collaboration, health care

Dr Tivener is currently a Clinical Instructor in the Sports Medicine and Athletic Training Department at Missouri State University. Please address all correspondence to Kristin Ann Tivener, MET, ATC, Department of Sports Medicine and Athletic Training, Missouri State University, 901 South National Avenue, PROF 160, Springfield, MO 65897. KTivener@MissouriState.edu.

Full Citation:

Tivener KA, Gloe DS. Designing simulations for athletic training students through interprofessional teaching collaboration. Athl Train Educ J. 2015;10(3):249-255. 


\title{
Designing Simulations for Athletic Training Students Through Interprofessional Teaching Collaboration
}

\author{
Kristin Ann Tivener, MET, ATC; Donna Sue Gloe, EdD, RN-BC
}

\section{INTRODUCTION}

Interprofessional education (IPE) and interdepartmental faculty collaboration are increasingly becoming more established and practiced elements within health professionals' education. ${ }^{1-4}$ Interprofessional education is a pedagogical approach in which students from 2 or more professions associated with health or social care engage in learning with, from, and about each other in order to prepare themselves to provide patient care in a collaborative team environment. ${ }^{5,6}$ The premise of IPE is that once health care professionals begin to work together in a collaborative manner, patient care will improve. ${ }^{6-8}$ The World Health Organization, ${ }^{8}$ the Institute of Medicine (IOM), ${ }^{9}$ and the American Public Health Association ${ }^{7}$ are a few of the many organizations that have supported IPE. The IOM has stated that "health professionals should be educated to develop patient-centered care as members of an interdisciplinary team" 9 and that "patients receive safer, high quality care when health care professionals work effectively in a team, communicate productively, and understand each other's roles."9 In 2003, the IOM published a report, "Health Professions Education: A Bridge to Quality," reflecting an interprofessional discussion involving 150 participants across many health care professions. ${ }^{9}$ This report established the need for IPE and consequently has driven many health care professional and educational organizations to move forward in establishing IPE among their members and students. ${ }^{6}$ Although the need for IPE has been well established, implementation of IPE into health professional education has significantly varied and has been slow to evolve. ${ }^{4-6,10,11}$ For example, a survey of schools and colleges of pharmacy in the United States revealed that $47 \%$ of them were not currently offering IPE. ${ }^{12}$ Experts feel one reason for the lack of IPE is that traditionally most health professional education takes place in silos, and even when students across different professions are learning common skills and content they do so without interaction with other programs because of the structure of the curricula. ${ }^{10}$ Additionally, the task of designing and implementing IPE is challenging given that collaborations (both professionally and educationally) require commitment on the part of the collaborators. ${ }^{1,3,10}$ Integrating concepts of different disciplines to create a single educational event requires extensive planning time commitments. ${ }^{10}$ However, it has been well documented ${ }^{3,13,14}$ that bringing together professionals of diverse but interrelated disciplines in IPE can enhance students' understanding of the health care system and the technical expertise each professional provides.

As evidence of the support for IPE, many accrediting bodies are now developing standards and guidelines for their respective health care professions to address the necessity for this collaborative approach in education. ${ }^{6}$ Specifically, the Liaison Committee on Medical Education, the accrediting body for medical schools in the United States and Canada, has 2 standards (ED-19 and ED-23) referring to interacting with other health care providers. ${ }^{15}$ The accrediting agency for baccalaureate and graduate nursing programs in the United States, the Commission on Collegiate Nursing Education, revised their standards in 2008 to include Essential VI (Interprofessional Communication and Collaboration for Improving Patient Health Outcomes), which focuses on IPE as a central competency. ${ }^{16}$ While multidisciplinary team approaches to health care education and practice have been recognized internationally since the mid-1980s, and despite the fact that evidence of the effectiveness of IPE in the United States has grown within the last 20 years, there has been limited research into the effects of collaborative efforts on athletic training education. ${ }^{10,17}$

Athletic training and nursing education programs prepare students for entry into unique and specific health care disciplines; however, these programs share similarities in required educational competencies, including the performance of cardiopulmonary resuscitation (CPR) techniques and procedures (National Athletic Trainers' Association Competency AC 12-18). ${ }^{18,19}$ In these professions, as well as other health care professions, simulation has been increasingly used as a teaching tool to provide students with opportunities to practice and learn in an environment that mimics the patient care experience as closely as possible. ${ }^{2,3,20,21}$ Simulation is defined as a technique that involves the combination of a person, device, or a set of conditions that replicates aspects of the real world in a fully interactive fashion. ${ }^{2,20,22}$ Even though both professions use simulation as a teaching and learning tool for this shared skill, literature is limited regarding the collaborative efforts among these professions. The goal of this article is to provide an example of an interprofessional teaching collaboration in which a simulation scenario was developed between athletic training and nursing education faculty members and to outline the observed benefits and barriers arising from this approach.

\section{SCENARIO DEVELOPMENT}

In 2012, 2 faculty members from the athletic training and nursing departments in a 4-year public master's-granting university collaborated in developing and implementing a simulation for athletic training students. The simulation was primarily being developed for students in the athletic training program. The athletic training faculty member requested collaboration with the nursing department faculty member, who served as coordinator of the simulation center and as a certified basic life support (BLS) instructor. The nursing faculty member also had years of experience in critical care nursing, often participating in the performance of CPR in the clinical setting, which played a key role in providing athletic training students with a nursing perspective during the simulation experience.

Faculty members initially met in order to communicate the goals of the simulation experience as well as to educate each other on individual backgrounds, experiences, and methods 
Figure. Cardiopulmonary resuscitation (CPR) simulation in an athletic training setting. Abbreviations: AED, automated external defibrillator; EMS, emergency medical services; ICU, intensive care unit; NPA, nasopharyngeal airway; OPA, oropharyngeal airway.

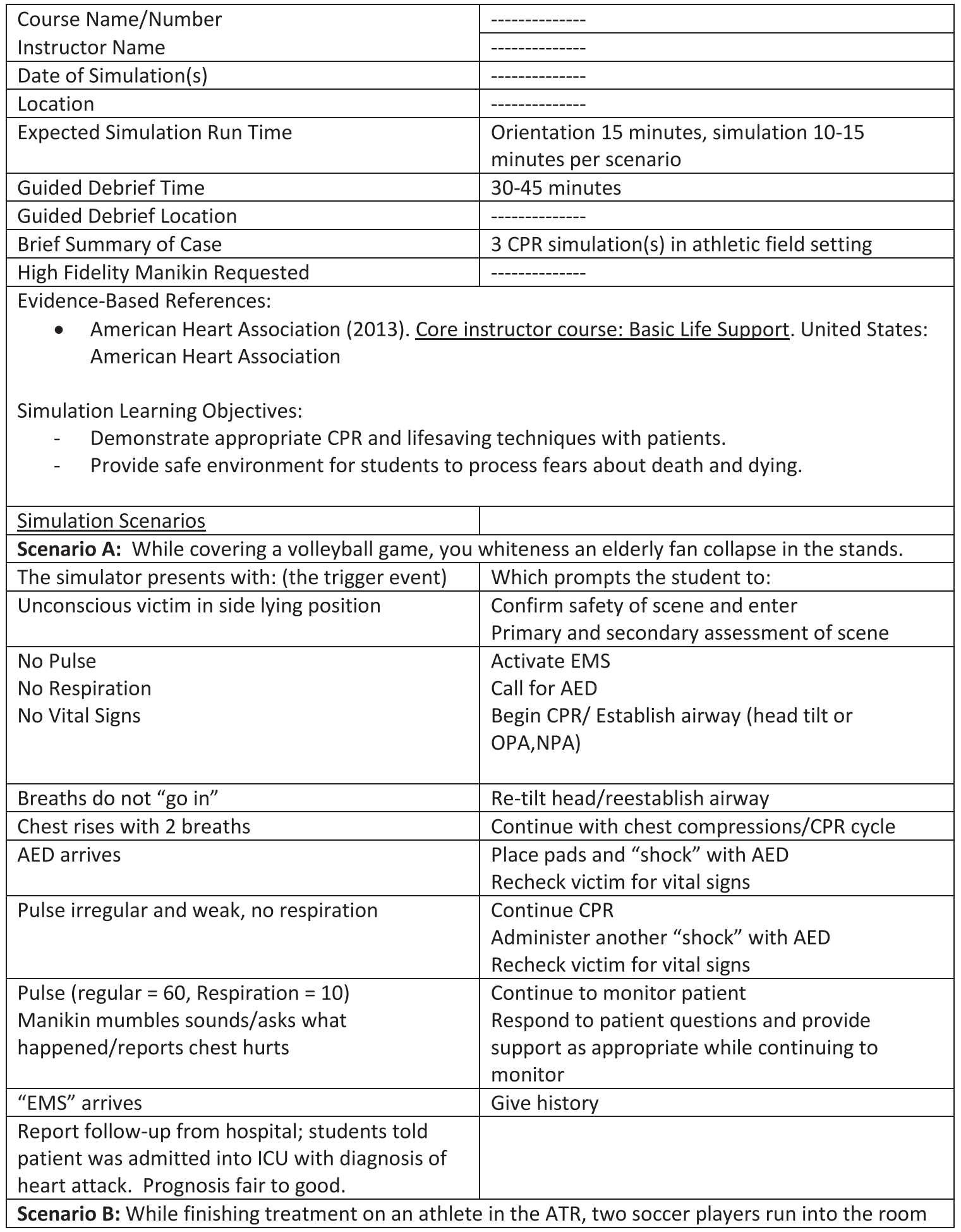

related to their specific disciplines. It was decided by both faculty members that the simulation experiences would use the university's Laerdal SimMan high-fidelity manikin in the nursing simulation lab. The nursing faculty member had expert knowledge on the capabilities of the high-fidelity manikins as well as experience in the operation of this technology. Over time, a scenario was developed as a means to bring the instructors together (see the Figure).

\section{METHOD}

Athletic training students took part in this BLS simulation as part of their clinical practicum course, which contained units that reviewed emergency skills. Scenarios took place over 3 different class days, and students were divided into 3 groups containing 6 students each. During each simulation lab day, students were paired, and 3 scenarios were presented. The scenarios included a parent who has a heart attack in the 
Figure. Continued.

\begin{tabular}{|c|c|}
\hline The simulator presents with: (the trigger event) & Which prompts the student to: \\
\hline $\begin{array}{l}\text { Unconscious victim lying prone with simulated } \\
\text { vomit in mouth, on face and clothing, and on } \\
\text { floor. }\end{array}$ & $\begin{array}{l}\text { Confirm safety of scene and enter } \\
\text { Primary and secondary assessment of scene }\end{array}$ \\
\hline $\begin{array}{l}\text { No Pulse } \\
\text { No Respiration } \\
\text { No Vital Signs }\end{array}$ & $\begin{array}{l}\text { Activate EMS } \\
\text { Call for AED } \\
\text { Use protected devices (gloves) } \\
\text { Suction device } \\
\text { Begin CPR; Establish airway (head tilt or } \\
\text { OPA,NPA) }\end{array}$ \\
\hline 2 rescue breaths "go in". chest rises & $\begin{array}{l}\text { Perform chest compressions, continue with CPR } \\
\text { cycles. }\end{array}$ \\
\hline AED arrives & Place pads and "shock" with AED \\
\hline $\begin{array}{l}\text { No Pulse } \\
\text { No Respiration } \\
\text { No Vital Signs }\end{array}$ & Continue CPR and AED \\
\hline "EMS" arrives & Continue CPR and give history \\
\hline $\begin{array}{l}\text { Follow up from hospital report; students told } \\
\text { patient was transported to emergency } \\
\text { department pronounced dead on arrival by } \\
\text { attending physician. }\end{array}$ & \\
\hline \multicolumn{2}{|c|}{$\begin{array}{l}\text { Scenario C: While covering a football game, two players collide during a tackle. The athlete on your } \\
\text { team does not get up after the hit. }\end{array}$} \\
\hline The simulator presents with: (the trigger event) & Which prompts the student to: \\
\hline Unconscious victim lying supine in full pads & $\begin{array}{l}\text { Confirm safety of scene and enter } \\
\text { Primary and secondary assessment of scene }\end{array}$ \\
\hline $\begin{array}{l}\text { No Pulse } \\
\text { No Respiration } \\
\text { No Vital Signs }\end{array}$ & $\begin{array}{l}\text { Activate EMS } \\
\text { Call for AED } \\
\text { Remove facemask } \\
\text { Begin CPR; Establish airway (head tilt or } \\
\text { OPA,NPA) }\end{array}$ \\
\hline 2 rescue breaths "go in". chest rises & Chest compressions, continue with CPR cycles. \\
\hline AED arrives & Place pads and "shock" with AED \\
\hline $\begin{array}{l}\text { No Pulse } \\
\text { No Respiration } \\
\text { No Vital Signs }\end{array}$ & Continue CPR and AED \\
\hline "EMS" arrives & Continue CPR and give history \\
\hline $\begin{array}{l}\text { Follow up from hospital report; patient was } \\
\text { admitted to the ICE in critical condition. They } \\
\text { expired the following morning with a cause of } \\
\text { death of traumatic brain injury. }\end{array}$ & \\
\hline
\end{tabular}

stands at a volleyball game, an unconscious athlete lying prone at a team dinner, and a football player who loses consciousness after colliding with another player. Two students participated in each scenario as health care providers, and the other students participated as observers in the session and recorded their interpretations of the actions taken during the scenario through a student observer record. Both the athletic training and nursing faculty members were present in the room only at the beginning of the scenario to introduce the background of the scene and then exited the room to control the high-fidelity manikin from behind a one-way glass-windowed control room from which they could watch and hear the students.

After the conclusion of the simulation, athletic training and nursing faculty reentered the room and brought all students, those who completed the scene and the student observers, together for a debriefing session. This faculty-facilitated discussion consisted of what was done well, identification of actions that could have been done differently, and the thought processes behind the decisions that were made. It was during this debriefing that athletic training students were 
able to learn from both the athletic training and nursing faculty as they shared their perspectives on the performance of the students through this interprofessional teaching collaboration.

During the debriefing, the students shared their reactions and the feelings they had before the simulation, during the scenario, and after the completion of their simulation experience. Research has shown that debriefing is an integral element of the simulation experience that allows participants to be led through a purposeful discussion so that learning can take place through analysis of events and decisions made during the simulation. ${ }^{23}$ The facilitator plays a crucial role in the debriefing by guiding the participants to think accurately about the experience and by putting it into a realistic perspective by providing direct and honest feedback. ${ }^{23}$ This process affords participants the opportunity to ask questions, identify strengths and weaknesses, and gain learning insights. ${ }^{21}$ In order to consolidate and confirm these learning insights, the students were asked to write a reflection paper 2 weeks after the simulation. In these papers, students were asked to provide a brief summary of their experience followed by a deep reflection including how they felt during the simulation, what they learned from the experience, and their overall reaction to the event. These papers were analyzed for themes and learning insights by both the athletic training and nursing faculty members using Dedoose software (SocioCultural Research Consultants, LLC, Los Angeles, CA). Dedoose is an application for analyzing qualitative and mixed-methods research and allows for sorting coded information into themes to analyze their frequency in the data. The text from the reflection papers was uploaded into the Dedoose software, and each of the researchers independently coded the qualitative data. The researchers then compared the independently coded results, and differences were resolved with discussion.

After comparison and discussion of the coded themes, both researchers felt the Dedoose software accurately achieved theme reporting. Common themes that emerged were (1) $100 \%$ of the students stated they were nervous before the scenario, describing their feelings with statements such as "I felt stressed and nervous at the beginning" and "I was scared I was going to mess up"; (2) students were able to suspend reality and participate in the situation, as evidenced by the fact that $80 \%$ of the students referred to the manikin as "my patient" or "the victim" and described their feelings as "upsetting" if the manikin "died" during the scenario.

Literature indicates that the ability for a student to effectively suspend disbelief and become immersed in a scenario has been described as a crucial element contributing to a realistic learning opportunity and positive educational outcome in simulation. ${ }^{21}$ The fact that students demonstrated strong emotional reactions to the simulation indicates that they took the scenarios seriously. Additionally, in referring to their manikin as "my patient," as described in the second theme, students demonstrated effective immersion into the simulation. Therefore, it can be concluded that the students acted in these simulations as they may have in actual clinical emergencies. This conclusion supports the notion that the simulation experience provided a realistic learning opportunity and led to a positive educational outcome.
The third theme to emerge as part of the reflection papers was that communication was important among $100 \%$ of the students during the scenario. As one student stated in the reflection paper, "We should have communicated more while providing care," and another stated "communication was important so we both knew what was going on and so that other health care providers who approached the scene knew exactly where we were at in providing care." Through the debriefing, the athletic training and nursing faculty used this interprofessional teaching opportunity to share clinical examples of how the element of communication is of great importance within each of these disciplines. Students were able to use these examples, as well as their own experiences in the simulation, to conclude the importance of this skill.

Additional themes that emerged from the Dedoose software with comparison discussion among the researchers were (4) that students felt it was a valued experience (100\% of the students described the simulation as "a great experience," indicating that it "surpass[ed] my expectations" and was a "great learning opportunity"); and (5) $70 \%$ of the students were able to have a deeper analysis of the experience over time, as evidenced by statements in the reflection papers. One student reflected

This really helped to show me how I would really act in an emergency situation. When the simulation ended, I had so much adrenaline going that I couldn't remember all the details about what happened. After the debriefing and thinking about my actions later, began to understand why or why not my actions were good in providing care.

Positive reflections over the simulation experience and the ability to have a deeper analysis of the experience over time demonstrate that the athletic training students enjoyed this activity. Reports ${ }^{24}$ on learner satisfaction demonstrate that as enjoyment in the activity increases, the amount of interaction of the learner, including overall engagement and creativity, also increases. This is significant, because it indicates the simulation experience provided students with a valuable opportunity that promoted critical thinking and active learning in the management of an emergency.

\section{BENEFITS OF INTERPROFESSIONAL COLLABORATIONS}

Individual department budget restraints combined with the large expense of high-fidelity simulation manikins and equipment often are limiting factors in using this type of simulation as a teaching method. ${ }^{3,25}$ The athletic training program did not have the same high-fidelity resources as the nursing program; therefore, throughout this interprofessional teaching collaboration athletic training students were able to have the opportunity to experience simulation with the equipment in this lab. In addition, through this activity the nursing lab was able to maximize its simulation use, thereby providing more justification for this resource.

In most athletic training settings, CPR is a high-risk, lowincidence event that clinicians rarely are required to perform. Therefore, athletic training students are not likely to have extensive clinical experiences with regard to this skill or with the death of an athlete, including long-term sequelae resulting from administering CPR. Nursing practice can quite often be 
the opposite, and depending on the practice setting (eg, Emergency Department and Intensive Care Unit), nurses are frequently involved in this high-risk event. The combined knowledge and experience of the 2 faculty types contributed to the realism of the simulation and enhanced the pedagogy of simulation. Specifically, the nursing faculty's experience and expertise in frequently performing CPR within their professional practice was a key component in providing athletic training students with the unique clinical perspective. Therefore, without both types of faculty, the 3 scenarios would have been lacking in content and realism. Faculty members from both disciplines identified this as one of the greatest benefits to the interprofessional teaching collaboration.

The faculty found the interprofessional teaching collaboration to be extremely beneficial in the athletic training student debriefing sessions after the BLS scenarios. The athletic training faculty was able to lead students in exploring situations that may arise in their settings, while the nursing faculty was able to provide relevant clinical experiences, including emotional reactions to the event as well as to the death of a patient. It was found through the student reflection papers that this collaborative effort from both disciplines in the debriefing was valued greatly by the athletic training students. For example, in one scenario, students responded to a football player in full pads. In providing care, the student removed the football helmet in order to have access to the patient's airway, which caused a cervical spine injury. During the debriefing after the simulation, the athletic training faculty emphasized the importance of removing the face mask and that this standard of care must be adhered to by all certified athletic trainers, and the nursing faculty described the complications that would likely be encountered by the patient as an inpatient in the hospital and during long-term care in terms of the management of a cervical spine injury.

The interprofessional teaching collaboration allowed the students to relate their actions to realistic clinical outcomes while reinforcing essential clinical competencies for certified athletic trainers. Using this discussion, the students reported that they "knew from class that they were supposed to remove the face mask" and "wished they made a better clinical decision but were so overwhelmed by this emergency situation they panicked, wanting to get to the airway as soon as possible since the patient was not breathing." Through this faculty-led discussion, the students were able to process the situation and learn that it is important to "put fears and the pressure of emergency situations aside in order to ensure things taught in class are remembered and put into practice."

Finally, the faculty found that through this interprofessional teaching collaboration, a mutual respect for each discipline was reinforced and a new perspective developed. Through the exploration of resources, tools, procedures, and methods within each discipline, the faculty discovered that there are numerous opportunities for true integration of the disciplines through IPE. Most significantly, the faculty identified that there could be many opportunities to develop true IPE activities for students by pairing both athletic training and nursing students in simulation designs. The faculty also found that collaboration led to research opportunities and increased interprofessional functioning.

\section{BARRIERS TO COLLABORATION}

The main barriers that were found through this interprofessional teaching collaboration were time and coordination. In order to fully develop a collaborative strategy that would maximize the simulation experience, a great deal of time was spent in sharing ideas. Athletic training and nursing faculty first met and shared disciplinary perspectives. The faculty discussed at great length clinical setting opportunities in athletic training; high-risk, low-incident events; and how to provide an experience that would challenge the skills, critical thinking, and emotional reactions of the students. Cardiopulmonary resuscitation can be a very emotional experience, and both faculty types felt that the simulation lab would be a great way for students to experience the emotions of finding a person breathless and pulseless, perform CPR, and cope with the positive (the patient lives) or negative (the patient dies or suffers severe disabilities) outcomes.

Coordination of the 2 disciplines initially presented a barrier. While these 2 disciplines are part of the same college within the university, currently there is little collaboration between the departments. Therefore, it was by chance that the 2 faculty members met and learned about the resources and teaching goals each possessed. The collaboration also required a great deal of critical and creative thinking in restructuring student activities affiliated with the established coursework.

\section{CONCLUSIONS}

The faculty found that interprofessional teaching collaboration in the BLS simulation scenarios was a positive experience that greatly enhanced the learning insights and clinical relevance for athletic training students. Though this required a great deal of time in terms of communication and coordination, the faculty felt that the benefits of collaboration greatly outweighed these barriers. Interprofessional collaboration provides opportunities to reach positive educational and scholarship outcomes. ${ }^{2,3,13}$ In addition, collaboration can maximize opportunities for using simulation labs and departmental resources. The athletic training and nursing faculty members plan on continuing their interprofessional teaching collaboration in the future by making the BLS simulation experience a permanent assignment in the course. Additionally, the athletic training and nursing faculty plan on developing interdepartmental simulation activities involving athletic training and nursing students working interprofessionally in response to an emergency cardiac scenario.

\section{REFERENCES}

1. Graybeal C, Long R, Scalise-Smith D, Zeibig E. The art and science of interprofessional education. J Allied Health. 2010; 39(3):232-237.

2. Robertson J, Bandali K. Bridging the gap: enhancing interprofessional education using simulation. J Interprof Care. 2008; 22(5):499-508.

3. Willhaus J. Interdepartmental simulation collaboration in academia: exploring partnerships with other disciplines. Clin Sim Nurs. 2010;6:231-232.

4. Carlisle C, Cooper H, Watkins C. "Do none of you talk to each other?": the challenges facing the implementation of interprofessional education. Med Teacher. 2004;26(6):545-552. 
5. Barr H, Koppel I, Reeves S, Hammick M, Freeth DS. Effective Interprofessional Education: Argument, Assumption and Evidence (Promoting Partnership for Health). Malden, MA: Blackwell Publishing Ldt; 2008.

6. Buring SM, Bhushan A, Broeseker A, et al. Interprofessional education: definitions, student competencies, and guidelines for implementation. Am J Pharm Educ. 2009;73(4):59.

7. Policy statement on promoting interprofessional education. American Public Health Association Web site. http://www. apha.org/policies-and-advocacy/public-health-policy-statements/ policy-database/2014/07/23/09/20/promoting-interprofessionaleducation. Accessed December 30, 2013.

8. World Health Organization. Learning together to work together for health. Report of a WHO study group on multiprofessional education of health personnel: the team approach. WHO Technical Report Series. 1988;769:3-72.

9. Greiner AC, Knebel E. Institute of Medicine. Committee on the Health Professions Education Summit. Health Professions Education: A Bridge to Quality. Washington, DC: National Academy Press; 2003.

10. Barnsteiner JH, Disch JM, Hall L, Mayer D, Moore SM. Promoting interprofessional education. Nurs Outlook. 2007; 55(3): 144-150.

11. Curran VR, Sharpe D, Flynn K, Button P. A longitudinal study of the effect of an interprofessional education curriculum on student satisfaction and attitudes towards interprofessional teamwork and education. J Interprof Care. 2010;24(1):41-52.

12. Grice G, Murphy J, Belgeri M, LaPlant B. Interprofessional education among schools of pharmacy. Am J Pharm Educ. 2008; 72(3):72.

13. Alberto J, Herth K. Interprofessional collaboration within faculty roles: teaching, service, and research. Online $J$ Issues Nurs. 2009; 14(2):1-15.

14. Dyer JA. Multidisciplinary, interdisciplinary, and transdisciplinary educational models and nursing education. Nurs Educ Perspect. 2003;24(4):186-188.

15. Liaison committee on medical education standards for accreditation of medical education programs leading to the MD degree.
Functions and Structure of a Medical School Web site. http:// www.acpe-accredit.org/pdf.Standards2000.pdf. Accessed December 30, 2013.

16. The essentials of baccalaureate education for professional nursing practice. American Association of Colleges of Nursing Web site. http://www.aacn.nche.edu/education-resources/ BaccEssentials08.pdf. Accessed December 30, 2013.

17. Reeves S, Freeth D, McCrorie P, Perry D. 'It teaches you what to expect in future ...': interprofessional learning on a training ward for medical, nursing, occupational therapy and physiotherapy students. Med Educ. 2002;36(4):337-344.

18. Board of Certification, Inc. BOC Role Delineation Study/Practice Analysis, Sixth Edition and NATA Athletic Training Education Competencies, Fifth Edition. http://www.bocatc.org/dev/images/ stories/educators/boc_rdpa6_and_nata_ec5_crosswalk_analysis_ 1212af.pdf. Accessed December 30, 2013.

19. Curriculum standards; 2013. American Association of Colleges of Nursing Web site. http://www.aacn.nche.edu/educationresources/curriculum-standards. Accessed December 30, 2013.

20. Gaba DM. The future vision of simulation in health care. Qual Saf Health Care. 2004;13(suppl 1):2-10.

21. Garrett B, MacPhee M, Jackson C. High-fidelity patient simulation: considerations for effective learning. Nurs Educ Perspect. 2010;31(5):309-313.

22. Scalese RJ, Obeso VT. Simulation technology for skills training and competency assessment in medical education. J Gen Int Med. 2008;23(1):46-49.

23. Lasater K. High-fidelity simulation and the development of clinical judgment: students' experiences. J Nurs Educ. 2007;46(6): 269-276.

24. Laschinger S, Medves J, Pulling C, et al. Effectiveness of simulation on health profession students' knowledge, skills, confidence and satisfaction. Int J Evid Based Healthc. 2008;6(3): 278-302.

25. Thidemann IJ, Ooderhamn O. High-fidelity simulation among bachelor students in simulation groups and use of different roles. Nurs Educ Today. 2013;12:1599-1604. 